\title{
SURFACE ROUGHNESS OF THIN WOOD VENEERS SLICED FROM LAMINATED GREEN WOOD LUMBER
}

\author{
Guangyao Li ${ }^{1}$, Qinglin $\mathrm{Wu}^{2, \star}$, Yanli He ${ }^{3}$, Zhikun Liu ${ }^{1}$
}

\begin{abstract}
Freshly-felled Chinese fir (Cunninghamia lanceolate), Masson Pine (Pinus massoniana) and Camphor Tree (Cinnamomum camphora) logs were reconstituted to form laminated lumber with moisture content above fiber saturation point by slicing, finger-jointing, gluing, and cold-pressing processes. The laminated lumber was then sliced into wood veneers, which were air-dried to about $15 \%$ moisture content. The surface roughness of the veneer was tested in comparison with two commercial engineered wood veneers using a stylus tracing method. The influence of the wood surface roughness was relatively small for the wood species chosen due to their similar densities. All roughness parameter values were consistently larger along the transverse direction compared with these along longitudinal direction. The values of surface roughness at the finger-joint region were higher than these that at the non-finger-joint region along both longitudinal direction and transverse direction. The two engineered wood veneers had surface roughness values noticeably smaller in the longitudinal direction, but their values in transverse direction were comparable and even larger compared with these of the prepared wood veneers including both non-finger-joint and finger-joint regions. Overall, the process of laminating finger-jointed green wood planks and subsequently slicing can be used to yield acceptable wood veneers with sufficient surface quality.
\end{abstract}

Keywords: Cinnamomum camphora, Cunninghamia lanceolate, finger joints, laminated lumber, moisture content, Pinus massoniana.

\section{INTRODUCTION}

Low-quality, small-diameter logs are currently reconstituted to form laminated lumber, which is then used to produce a variety of thin wood veneers to replace precious solid wood with natural texture and color. It has become one of the practical ways to supplement natural decorative veneers (Peng and Wang 2004, Liu et al. 2003, Deng and Liu 2010, Yu and Yu 2013, Dumitrascu et al. 2013). Surface roughness of wood and wood-based products is one of the most important factors for decorative wood elements targeted for interior and exterior uses. Low surface quality not only negatively affects the appearance of the finished products, but also affects further manufacturing processes including glue adhesion, and adhesive strength (Budakci et al. 2007, Aslan et al. 2008, Coelho et al. 2008).

Wood material is highly heterogeneous at the microscopic level, and the surface quality (e.g., roughness) of wood is affected by its anatomic feature. Thus, it is quite complicated to make a detailed assessment of wood surface quality (Hendarto et al. 2006). Among various testing techniques for

\footnotetext{
${ }^{1}$ School of Engineering, Zhejiang Agriculture and Forestry University, Zhejiang, China.

${ }^{2}$ School of Renewable Natural Resources, Louisiana State University Agricultural Center, Baton Rouge, USA.

${ }^{3}$ School of Forestry, Hebei Agricultural University, Hebei, China.

"Corresponding author: wuqing@1su.edu

Received: 06.04.2017 Accepted: 16.09.2017
} 
determining surface roughness of wood and wood composites, the stylus method has been most widely used in the past studies (Hiziroglu 1996, Zhong et al. 2013). The stylus method can help measure actual surface profile, from which standard numerical roughness parameters can be derived (Kilic et al. 2006). With this test method, the roughness characteristics of the sliced thin wood veneer surface can be assessed by determining the shape, height, and width of the roughness peaks and valleys on wood surface as influenced by wood processing operations or by inherent anatomical structural properties (Magoss 2008).

The roughness of solid wood surface is highly related to processing conditions and wood properties, including species (hardwood versus softwood), density (low versus high), moisture content (MC), annual ring pattern, and cell type and structure, earlywood and latewood percentage ratio, and number and distribution of tracheid and vessel elements (Wang et al. 2005, Magoss 2008, Brémaud et al. 2011, Csanády et al. 2015). Several studies have been conducted to investigate the influence of machine processing (i.e., sawing, sanding, and planning), early- and late-wood distribution, and material directions (i.e., longitudinal, radial and tangential) on the surface roughness quality of wood and laminated wood composites (Malkoçoğlu 2007, Dundar et al. 2008, Kilic et al. 2006, Sulaiman et al. 2009).

Wood cell walls take on a greater tenacity at high MCs. Free water in the cell lumen helps somewhat strengthen the toughness of wood, reduce the cutting resistance (e.g., during slicing), decrease the damage to the cell wall, and improve the quality of sliced wood veneer (Li et al. 2015, Liu et al. 2003). Thus, if laminated wood lumber at MC well above fiber saturation point can be successfully sliced to yield high surface quality veneers, significant saving can be achieved in raw lumber processing (e.g., kiln-drying) and veneer manufacturing (e.g., slicing dry laminated lumber with more energy input). In this work, fresh wood logs were reconstituted to form laminated wood lumber by slicing, finger-jointing, gluing and cold pressing. The lumber was subsequently sliced to produce wood veneers. The objective of this work was to measure the surface roughness of the wood veneers and to examine if the processed veneers can meet the requirements of subsequent processing technology.

\section{MATERIALS AND METHODS}

\section{Experimental Materials and Sample Preparation}

The freshly-felled Chinese fir (Cunninghamia lanceolate Hook.), Masson Pine (Pinus massoniana Lamb.) and Camphor Tree (Cinnamomum camphora) logs were used as raw material. The green logs were sliced into thin planks, which were cross-cut to remove any knots and other defect and then finger-jointed as shown in Figure 1. The machining variables of finger jointing operation included the milling cutter thickness of 4,2 $\mathrm{mm}$ (equal to milled tenon's pitch), milling cutter tip width of $0,85 \mathrm{~mm}$ (equal to milled tenon's slot bottom width), milling cutter tip angle of $9,77^{\circ}$ (equal to milled tenon's wedge angle), and the slope of finger-joint's edge of 1/11,7 (related to the cutter tip slope). Figure 1a shows the lamination process using individual wood species (Chinese fir, Masson pine, and Camphor wood). Figure $1 \mathrm{~b}$ shows the lamination process for using combined wood species (alternating finger-jointed Masson pine and Camphor wood). The laminated lumbers at MC about $40 \%$ were sliced into thin veneers parallel to the radial face of the lumber. The veneer size was $2550 \mathrm{~mm}$ in length $\mathrm{x} 450 \mathrm{~mm}$ in width $\mathrm{x} 0,38 \mathrm{~mm}$ in thickness. The veneers were airdried to a $\mathrm{MC}$ about $15 \%$, and the dry veneer samples were taken for surface roughness testing.

For a comparative purpose, commercial engineered wood veneers $(0,38 \mathrm{~mm}$ in thickness) from Triplochitin scleroxylon (designated as EWV1) and Tilia amurensis Rupr (designated as EWV2) were selected. The veneers from both species groups were sliced from their respective laminated lumber, which was made up of single component $0,8 \mathrm{~mm}$ thick planks. The raw lumber material was glued by a two-component polyvinyl acetate (PVA) adhesive. The end pressure of the finger joint was 3,5 $\mathrm{MPa}$ and the joints were then cold pressed to form square laminates. The size of sliced veneer from the large-scale production process was $2550 \times 450 \times 0,38 \mathrm{~mm}$. 

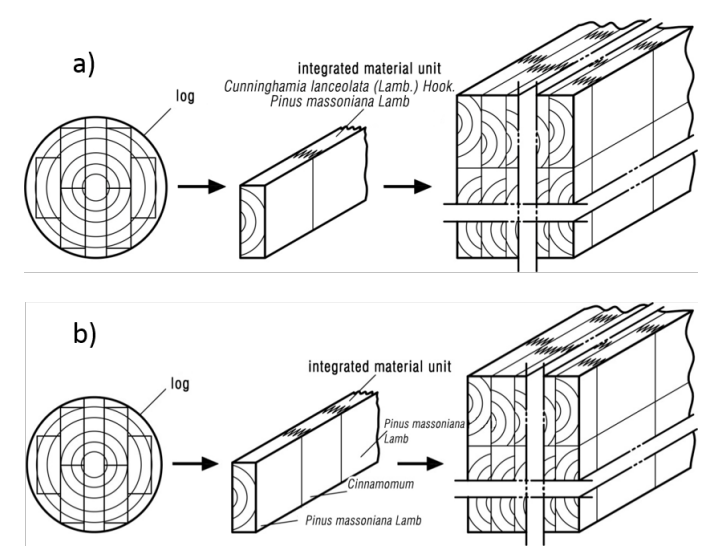

Figure 1. Schematic diagram of manufacturing laminated wood lumber with $\mathrm{MC}$ above fiber saturation point. a) lamination process using individual wood species; and b) lamination process for using combined wood species.

\section{Surface Roughness Test Apparatus and Method}

The veneer specimens for surface roughness testing were laterally cut from the large dry veneer sheets as shown in Figure 2. The planning was performed with a cabinet single-axed straight-knife peripheral planer, equipped with two freshly-sharpened knives installed in a $3000 \mathrm{rpm}$ cutter-head. The planer was set to work at $12 \mathrm{~m} / \mathrm{min}$ feed speed, which resulted in approximately 10 knife marks per $25 \mathrm{~mm}$. Knife rake and clearance angles were set to $12^{\circ}$ and $15^{\circ}$, respectively. Planer feeding was carried out parallel to the radial face of the lumber. The sample sections were from two ends and central part of each large veneer. Each surface roughness specimen was measured at the 5 selected positions with no-finger joints (NFJs - original wood surface) and 5 selected positions with finger-joints (NJs5 measurements at each position) along both longitudinal direction (LD) and transverse direction (TD). The average value and standard deviation for each parameter were established and reported.

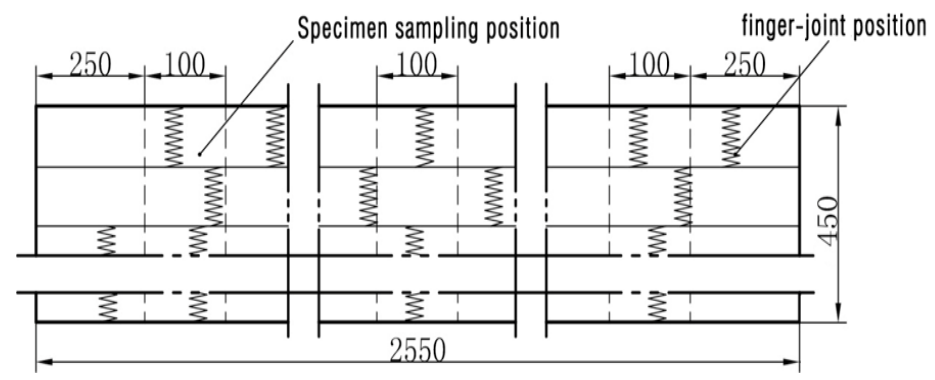

Figure 2. Schematic diagram of the sliced wood veneers for surface roughness testing (unit shown as $\mathrm{mm})$.

A model JB-5C (Shanghai Optical Instrument Factory Co., Ltd., Shanghai, China) stylus surface roughness profilometer was used to measure the roughness of the prepared veneer surfaces. The measuring conditions of the surface roughness included sampling length of $2,5 \mathrm{~mm}$, evaluation length of $12,5 \mathrm{~mm}$ (five times of the sampling length), and scanning speed of $0,5 \mathrm{~mm} / \mathrm{sec}$. The profile filter was an ISO 2CR Filter and stylus tip radius was $10 \mathrm{um}$. The surface roughness parameters include the profile's arithmetic mean deviation (i.e., $R a, \mu \mathrm{m}$ ), the profile's maximum height (i.e., $R z, \mu \mathrm{m}$ ), the profile's average distance of the microscopic unevenness $(R S m, \mu \mathrm{m})$ and the profile's root mean square deviation $(R q, \mu \mathrm{m})$ were determined and used to quantify the veneer surface quality. Among the five parameters, $R a$ and $R z$ are most often used to characterize a wood surface (Kilic et al. 2006). 


\section{RESULTS AND DISCUSSION}

\section{Typical Surface Roughness Profiles}

Figure 3 shows two representative surface roughness profiles from the Chinese fir wood veneers sliced fromlaminatedwoodlumberatgreen(alongtheTD withandwithoutfinger-joints). Themeasurementyielded surface roughness profile for the selected parameter and a summary of the numerical values of different parameters. As shown, the regions that included finger-joints had an apparent larger surface roughness values, compared with the regions without finger-joints. Similar results were seen for other veneer types.

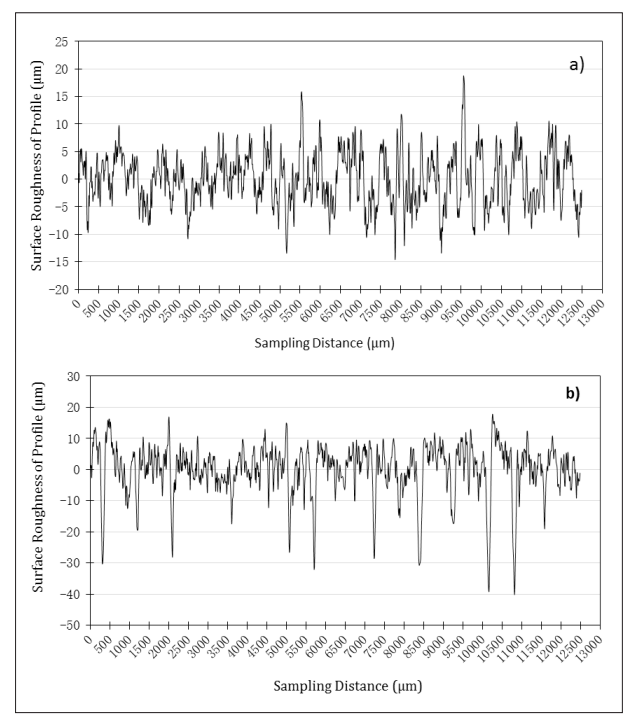

Figure 3. Typical transverse section surface roughness profile of the Chinese fir (Cunninghamia lanceolata) veneer samples sliced from laminated lumber at green. a) with no-finger joints, and b) with finger-joints.

\section{Measured Veneer Surface Roughness}

Table 1 lists summarized surface roughness parameters from different veneers. The mean wood moisture contents when the laminated lumber were sliced are respectively $40,2 \% ; 42,1 \%$; and $43,3 \%$ for Wood $_{\text {A }}-$ Chinese fir, Wood $_{B}-$ Camphor Tree, and Wood ${ }_{C}$ - Masson Pine and Camphor wood combination.

\section{Effect of wood type}

Among the three types of wood veneers $\left(\operatorname{Wood}_{A}\right.$, Wood $_{B}$, and Wood $\left._{C}\right)$, the surface roughness parameters in the no-finger joint (NFJ) region (i.e., original wood surface) varied inconsistently along both LD and TD. For example, the mean $R a$ values for veneers from $\operatorname{Wood}_{\mathrm{A}}$, Wood $_{\mathrm{B}}$, and Wood $_{\mathrm{C}}$ are, respectively 13,$55 ; 9,55$ and $14,57 \mu \mathrm{m}$ in the LD and 19,$87 ; 11,19$ and $14,72 \mu \mathrm{m}$ in TD. Similar trends of variations are seen for parameters $R z, R s m$, and $R q$. Thus, the effect of wood type on surface roughness data seemed to be small for the species of wood chosen. The basic wood densities for Chinese pine, Masson pine, and Camphor wood are generally similar in the range of $0,40-0,50 \mathrm{~g} /$ $\mathrm{cm}^{3}$ depending on the source. Thus, the chosen wood species had much similar response to slicing at green conditions, leading to overall similar surface roughness. Kilic et al. (2006) showed that beech (density $=0,70 \mathrm{~g} / \mathrm{cm}^{3}$ ) and Aspen $\left(\right.$ density $\left.=0,40 \mathrm{~g} / \mathrm{cm}^{3}\right)$ wood did show surface roughness value difference ( $R z$ parameter) in both radial and tangential directions given similar processing conditions (i.e., aspen wood with smoother surface). Thus, wood density difference played a more significant role in controlling shrinkage and swelling characteristics of wood, leading to different surface properties. 
Table 1. A summary of the surface roughness parameters for various wood veneers sliced from laminated wood lumber at green.

\begin{tabular}{|c|c|c|c|c|c|}
\hline \multirow{2}{*}{ Parameters $^{\mathrm{a}}$} & \multirow{2}{*}{$\begin{array}{l}\text { Test } \\
\text { Area }^{\mathrm{b}}\end{array}$} & \multirow{2}{*}{$\begin{array}{c}\text { Test } \\
\text { Direction }^{\mathrm{c}}\end{array}$} & Wood $_{A}{ }^{d}$ & $\operatorname{Wood}_{B}{ }^{d}$ & Wood $_{C}{ }^{d}$ \\
\hline & & & $40,2 \% \mathrm{MC}$ & $42,1 \% \mathrm{MC}$ & $43,3 \% \mathrm{MC}$ \\
\hline \multirow{4}{*}{$\begin{array}{c}R a \\
(\mu \mathrm{m})\end{array}$} & \multirow{2}{*}{ NFJ } & LD & $13,55(0,55)$ & $9,59(0,26)$ & $14,57(0,06)$ \\
\hline & & TD & $19,87(0,36)$ & $11,19(0,98)$ & $14,72(0,38)$ \\
\hline & \multirow{2}{*}{ FJ } & LD & $18,76(0,61)$ & $11,33(0,31)$ & $15,36(0,52)$ \\
\hline & & TD & $22,89(0,37)$ & $13,85(1,03)$ & $15,85(1,33)$ \\
\hline \multirow{4}{*}{$\begin{array}{c}R z \\
(\mu \mathrm{m})\end{array}$} & \multirow{2}{*}{ NFJ } & LD & $77,31(5,19)$ & $78,37(11,32)$ & $97,84(1,00)$ \\
\hline & & TD & $109,08(9,45)$ & $85,98(11,01)$ & $102,11(3,56)$ \\
\hline & \multirow{2}{*}{ FJ } & LD & $85,78(8,11)$ & $82,35(12,89)$ & $100,99(9,87)$ \\
\hline & & TD & $115,32(8,18)$ & $93,21(12,03)$ & $108,78(2,90)$ \\
\hline \multirow{4}{*}{$\begin{array}{l}R S m \\
(\mu \mathrm{m})\end{array}$} & \multirow{2}{*}{ NFJ } & LD & $0,217(0,017)$ & $0,247(0,018)$ & $0,267(0,004)$ \\
\hline & & TD & $0,324(0,018)$ & $0,232(0,014)$ & $0,225(0,006)$ \\
\hline & \multirow{2}{*}{ FJ } & LD & $0,276(0,018)$ & $0,301(0,012)$ & $0,237(0,012)$ \\
\hline & & TD & $0,404(0,011)$ & $0,263(0,013)$ & $0,309(0,012)$ \\
\hline \multirow{4}{*}{$\begin{array}{c}R q \\
(\mu \mathrm{m})\end{array}$} & \multirow{2}{*}{ NFJ } & LD & $16,67(0,56)$ & $12,31(0,16)$ & $18,08(0,15)$ \\
\hline & & TD & $23,88(0,11)$ & $13,99(1,23)$ & $18,55(0,60)$ \\
\hline & \multirow{2}{*}{ FJ } & LD & $20,12(0,62)$ & $16,31(0,22)$ & $21,13(0,43)$ \\
\hline & & TD & $27,39(0,21)$ & $17,21(0,47)$ & $23,58(1,39)$ \\
\hline
\end{tabular}

Notes: ${ }^{a} \mathrm{Ra}$ is the arithmetic mean deviation, $\mathrm{Rz}$ is the maximum height, $\mathrm{RSm}$ is the average distance microscopic unevenness, and $\mathrm{Rq}$ is the root mean square deviation. ${ }^{\mathrm{b}} \mathrm{NFJ}$ - no finger joint, $\mathrm{FJ}$ - finger joint. ${ }^{\mathrm{c}}$ LD-longitudinal direction, TD- transverse

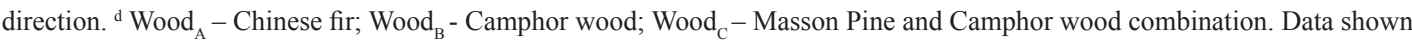
are mean and standard deviation.

\section{Effect of test direction}

The average surface roughness values of the sliced wood veneers from the same material in the different grain directions (longitudinal versus transverse) varied significantly (Table 1). All roughness parameter values are consistently larger along the TD compared with these along the LD. For example, the mean $R z$ values for veneers from $\operatorname{Wood}_{\mathrm{A}}$, Wood $_{\mathrm{B}}$, and $\operatorname{Wood}_{\mathrm{C}}$ in NFJ region are, respectively 77,31; 78,37 and 97,84 $\mu \mathrm{m}$ in the $\mathrm{LD}$ and 109,$08 ; 85,98$ and $102,11 \mu \mathrm{m}$ in TD. Similar trends of variations are seen for parameters $R a, R s m$, and $R q$. de Moura et al. (2014) reported surface roughness data for Eucalyptus grandis wood (heat treated) after machining. They showed that wood across the grain was much rougher after planning and sanding. This work showed a similar behavior with slicing at green condition and subsequent drying. As the wood is a non-homogeneous material, its expansion and shrinkage deformation are different along tangential direction (the largest), radial direction (the second), and longitudinal direction (the smallest). Thus, the differential shrinkage led to differences in the surface roughness values along different grain directions.

\section{Effect of Finger-jointing}

The values of surface roughness in the FJ region were higher than these in the NFJ region along both LD and TD. For the Chinese fir, Camphar, and Masson pine-Camphor wood veneers, the maximum values of the parameter $R a$ are, respectively 22,89; 13,85 and 15,85 $\mu \mathrm{m}$ (along TD within FJ region). The corresponding values for the parameter $R z$ are 115,32; 93,27 and 108,78 $\mu \mathrm{m}$ (along TD within FJ region). As there exists difference in the structure and density of different timbers, the state of stress experienced by each type of wood varied during finger jointing and subsequent slicing. In order to make firm and tight finger joints, the fitness ratio value of the joint must be positive. When lumber was jointed along the length, the body of the fingers was compressed and the compression deformation was built in the finger region. However, the compressive stresses were released when the lamination lumber was sliced into thin wood veneers, causing various degrees of expansion near the finger joint, which led to increased surface roughness. Nevertheless, due to small finger-joints used, the resulting surface roughness variation was not significant in practice, 
which had small negative effect on the subsequent application of the sliced thin wood veneers.

\section{Comparison with EWVs}

Table 2 shows surface roughness data $(R a$ and $R z)$ from the two commercial engineered wood veneers (EWVs). Overall, ENV2 from Tilia amurensis was slightly rougher compared with EWV1 from Triplochitin scleroxylon in terms of both $R a$ and $R z$ values. This could be related to the difference in wood properties of the two species, given the lamination and slicing processes the same.

Table 2. Surface Roughness Data of Sliced Commercial Wood Veneers from Triplochitin scleroxylon and Tilia amurensis.

\begin{tabular}{|c|c|c|c|c|}
\hline $\begin{array}{l}\text { Roughness } \\
\text { Parameters }\end{array}$ & $\begin{array}{c}\text { Test } \\
\text { Direction }^{\mathrm{a}}\end{array}$ & $\begin{array}{c}\text { Maximum } \\
\text { Value }\end{array}$ & $\begin{array}{l}\text { Minimum } \\
\text { Value }\end{array}$ & $\begin{array}{l}\text { Mean } \\
\text { Value }\end{array}$ \\
\hline \multicolumn{5}{|c|}{ Sliced Wood Veneers - Triplochitin scleroxylon } \\
\hline \multirow{2}{*}{$\begin{array}{c}R a \\
(\mu \mathrm{m})\end{array}$} & LD & 7,232 & 6,184 & 6,635 \\
\hline & TD & 15,713 & 11,546 & 13,922 \\
\hline \multirow{2}{*}{$\begin{array}{c}R z \\
(\mu \mathrm{m})\end{array}$} & LD & 45,591 & 34,583 & 40,793 \\
\hline & TD & 98,980 & 82,137 & 90,028 \\
\hline \multicolumn{5}{|c|}{ Sliced Wood Veneers - Tilia amurensis } \\
\hline \multirow{2}{*}{$\begin{array}{c}R a \\
(\mu \mathrm{m})\end{array}$} & LD & 7,872 & 7,075 & 7,494 \\
\hline & TD & 20,741 & 20,577 & 20,673 \\
\hline \multirow{2}{*}{$\begin{array}{c}R z \\
(\mu \mathrm{m})\end{array}$} & LD & 48,203 & 37,964 & 44,331 \\
\hline & TD & 120,730 & 115,683 & 118,475 \\
\hline
\end{tabular}

Comparative plots of $R a$ and $R z$ values for all five veneers including three manufactured wood veneers and two EWVs are shown in Figure 4 (NFJ region) and Figure 5 (FJ region). The data shows that surface roughness values were noticeably smaller for the two EWV groups in the LD (Figure 4 $\mathrm{a}: R a$ and Figure $4 \mathrm{~b}: R z$ ). For example, $R a$ values varied from 6184 to $7232 \mu \mathrm{m}$ for EWV1 and 7075 to $7872 \mu \mathrm{m}$ for EWV2. The corresponding mean values for $\operatorname{Wood}_{\mathrm{A}}$, Wood $_{\mathrm{B}}$, and $\operatorname{Wood}_{\mathrm{C}}$ are, respectively 13,$55 ; 9,59$ and $14,57 \mu \mathrm{m}$. However, the roughness data from the three wood veneers manufactured were more comparable and even smaller than these of EWVs (especially EWV2) in TD for both NFJ and FJ regions. Thus, the process of laminating finger-jointed green wood planks and subsequently slicing can be used to yield acceptable wood veneers with sufficient surface quality. The process can lead to significant saving in raw lumber processing (e.g., kiln-drying) and veneer manufacturing (e.g., slicing dry laminated lumber with more energy input).

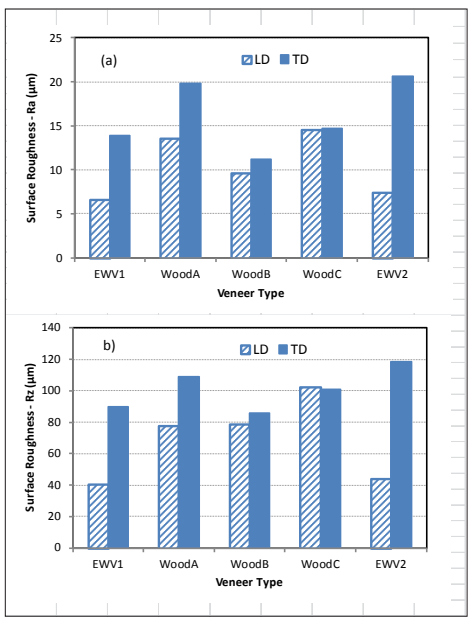

Figure 4. Comparison of surface roughness data from various veneers with no-finger joint region for Wood $_{\mathrm{A}}$, Wood $\mathrm{B}$ and Wood $_{\mathrm{C}}$. ENV1 and EWV2 are engineered wood veneers from Triplochitin scleroxylon and Tilia amurensis, respectively. a) $R a$ and b) $R z$. 


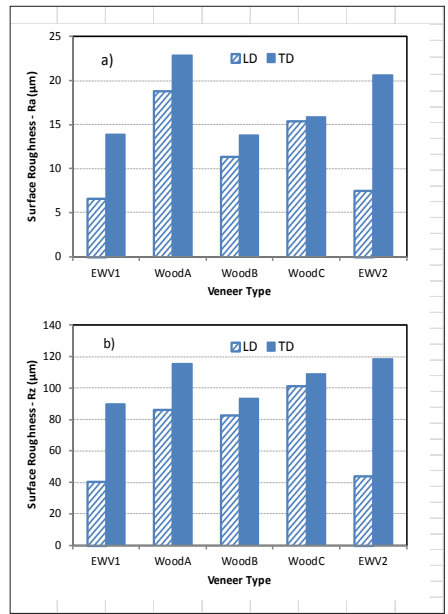

Figure 5. Comparison of surface roughness data from various veneers with finger joint region for $W_{\mathrm{A}}$, Wood $_{B}$ and Wood $\mathrm{C}_{\mathrm{C}}$. ENV1 and EWV2 are engineered wood veneers from Triplochitin scleroxylon and Tilia amurensis, respectively. a) $R a$ and b) $R z$.

\section{CONCLUSIONS}

The green Chinese fir, Masson pine and Camphor tree logs were successfully reconstituted and sliced to produce wood veneers. The surface roughness of the veneers at $15 \% \mathrm{MC}$ was studied in comparison with two commercial EWVs. The following conclusions can be reached:

The influence of wood type on surface roughness data was relatively small for the wood species chosen in the study due to their similar densities.

All roughness parameter values were consistently larger along TD compared with these along LD.

The surface roughness data at the finger-joint region were higher these that at the non-finger-joint region along both $\mathrm{LD}$ and $\mathrm{TD}$, probably due to the release of stresses generated during finger jointing processes.

The two EWV veneers had surface roughness values noticeably smaller for in the LD, but their values in TD were comparable and even larger compared with these of the prepared wood veneers including both NFJ and FJ regions.

Overall, the process of laminating finger-jointed green wood planks and subsequently slicing can be used to yield acceptable wood veneers with sufficient surface quality. The process can lead to significant saving in raw lumber processing (e.g., kiln-drying) and veneer manufacturing (e.g., slicing dry laminated lumber with more energy input).

\section{REFERENCES}

Aslan, S.; Coşkun, H.; Kılıç, M. 2008. The effect of the cutting direction, number of blades and grain size of the abrasives on surface roughness of Taurus cedar (Cedrus Libani A. Rich.) woods. Build Environ 43:696-701.

Brémaud, I.; Gril, J,; Thibaut, B. 2011. Anisotropy of wood vibrational properties: dependence on grain angle and review of literature data. Wood Sci Technol 45:735-754.

Budakci, M.; Gurleyen, L.; Cinar, H.; Korkut, S. 2007. Effect of Wood Finishing and Planing 
on Surface Smoothness of Finished Wood. J Appl Sci 7:2300-2306.

Coelho, C.L.; Carvalho, L.M.H.; Martins, J.M.; Costa, C.A.V.; Masson, D.; Meausoone, P. J. 2008. Method for evaluating the influence of wood machining conditions on the objective characterization and subjective perception of a finished surface. Wood Sci Technol 42:181-195.

Csanády, E.; Magoss, E.; Tolvaj, L. 2015. Surface Roughness of Wood. In: Quality of Machined Wood Surfaces. Springer International Publishing. Cham, pp 183-236. ISBN:978-319-22418-3.

de Moura, G. P.; de Figueired, J. V.; de Moura, L F.; Nolasco, A M.; de Carvalho, A. M.; Garcia, R. A. 2014. Surface roughness of heat treated Eucalyptus grandis wood. Maderas-Cienc Tecnol 16(1): 3 -12.

Deng, H.; Liu, Y. 2010. Study on Environmental-Friendly Dyeing Processes of Fast-Growing Plantation Veneers. In: $20104^{\text {th }}$ International Conference on Bioinformatics and Biomedical Engineering. IEEE, pp 1-4.

Dumitrascu, A.E.; Ciobanu, V.D.; Lepadatescu, B. 2013. Valorization of Wood Resources for the Cutting of Decorative Veneer in the Context of Sustainable Development of Romanian Forests. BioResources 8:4298-4311.

Dundar, T.; Ayrilmis, N.; Candan, Z. 2008. Evaluation of surface roughness of laminated veneer lumber (LVL) made from beech veneers treated with various fire retardants and dried at different temperatures. For Prod J 78:71-76.

Hendarto, B.; Shayan, E.; Ozarska, B.; Carr, R. 2006. Analysis of roughness of a sanded wood surface. Int J Adv Manuf Technol 28:775-780.

Hiziroglu, S. 1996. Surface roughness analysis of wood composites: A stylus method. For Prod J 46:67-69.

Kilic, M.; Hiziroglu, S.; Burdurlu, E. 2006. Effect of machining on surface roughness of wood. Build Environ 41:1074-1078.

Li, G.; Lv, Z.; Liu, Z. 2015. A preliminary study on the main mechanical properties of the high moisture content wood after finger-jointed. J Northwest For Univ 30:224-227.

Liu, Z.; Li, Y.; Du, C.; Zhang, Y. 2003. A study on production technology of sliced bamboo veneer. J Zhejang For Coll 20:227-231.

Magoss, E. 2008. General Regularities of Wood Surface Roughness. Acta Silvatica et Lignaria Hungarica 4:81-93.

Malkoçoğlu, A. 2007. Machining properties and surface roughness of various wood species planed in different conditions. Build Environ 42:2562-2567.

Peng, L.; Wang, J. 2004. A study on processing edge jointed veneer. China Wood Ind 18:72-76.

Sulaiman, O.; Hashim, R.; Subari, K.; Liang, C.K. 2009. Effect of sanding on surface roughness of rubberwood. J Mater Process Technol 209:3949-3955.

Wang, M.; Wang, J.; Li, L. 2005. Roughness and roughness sense of wood surface from different machining processes. Journal Beijing Forestry University 27:14-18.

Yu, W.; Yu, Y. 2013. Development and prospect of wood and bamboo scrimber industry in China. China Wood Industry 27:5-8.

Zhong, Z.W.; Hiziroglu, S.; Chan, C.T.M. 2013. Measurement of the surface roughness of wood based materials used in furniture manufacture. Measurement 46 1482-1487. 